\title{
Free radicals and metal ions in health and disease
}

\section{By Barry Halliwell, Department of Biochemistry, King's College (KQC), University of London, Strand, London $W C_{2} R 2 L S$}

\section{Background: the oxygen radicals}

Free-radical reactions have been implicated in many diseases. In the present paper I will try to give a brief historical introduction to developments in the free-radical field and then try to explain where our own research work has fitted in and in what directions it is going.

A radical is any species containing one or more unpaired electrons, i.e. electrons present alone in atomic or molecular orbitals. Usually, the presence of unpaired electrons is associated with increased reactivity. Some radicals are not very reactive but others are very reactive indeed. Possibly the most reactive radical species to form in living organisms is the hydroxyl radical, $\mathrm{OH}^{\circ}$.

The easiest way of making $\mathrm{OH}^{*}$ is simply to take water and expose it to high-energy ionizing radiation, whereupon the water molecule splits and one of the products is $\mathrm{OH}^{\circ} . \mathrm{OH}^{*}$ will attack almost any biological molecule that it is generated next to. For example, $\mathrm{OH}^{*}$ causes strand breaks in DNA, hydroxylates purine and pyrimidine bases, and attacks membrane lipids and proteins. Indeed, $\mathrm{OH}^{*}$ formation is known to be responsible for much of the damage that ionizing radiation does to living organisms. Since most of a cell is water, on irradiation most of the energy is absorbed by the water and produces $\mathrm{OH}^{\circ}$, which causes substantial damage.

Unfortunately, the radical reactions are not finished when the $\mathrm{OH}^{*}$ has attacked something. Fig. I shows what can happen when $\mathrm{OH}^{*}$ attacks a polyunsaturated fatty acid (PUFA) side-chain in a membrane lipid. If $\mathrm{OH}^{\circ}$ is formed close to a membrane, it tends to attack the PUFA side-chains in the membrane lipids and abstract an atom of hydrogen $\left(\mathrm{H}^{*}\right)$ to form water. This reaction removes the $\mathrm{OH}^{*}$, but leaves behind in the membrane another type of radical species, a carbon-centred radical. This can undergo various other reactions, including a reaction with molecular oxygen to form a third type of radical species, the peroxy radical. Peroxy radicals can react with another membrane fatty acid side-chain (Fig. $\mathrm{I}$ ), converting themselves into lipid peroxides. This is achieved by further $\mathrm{H}^{*}$ abstraction, forming another carbon-centred radical that can react with more $\mathrm{O}_{2}$ and carry on the reaction. Hence $\mathrm{OH}^{-}$attack on a membrane system can start off a radical chain reaction known as lipid peroxidation (Fig. 1 ).

A lipid peroxide is obviously more polar than anything that should be present in the hydrophobic interior of a biological membrane. Lipid peroxidation diminishes membrane fluidity, increases non-specific permeability to ions (e.g. $\left.\mathrm{Ca}^{2+}\right)$ and may inactivate membrane-bound enzymes. Further, in the presence of various kinds of 
Fatty acid with three double bonds

Hydrogen abstraction

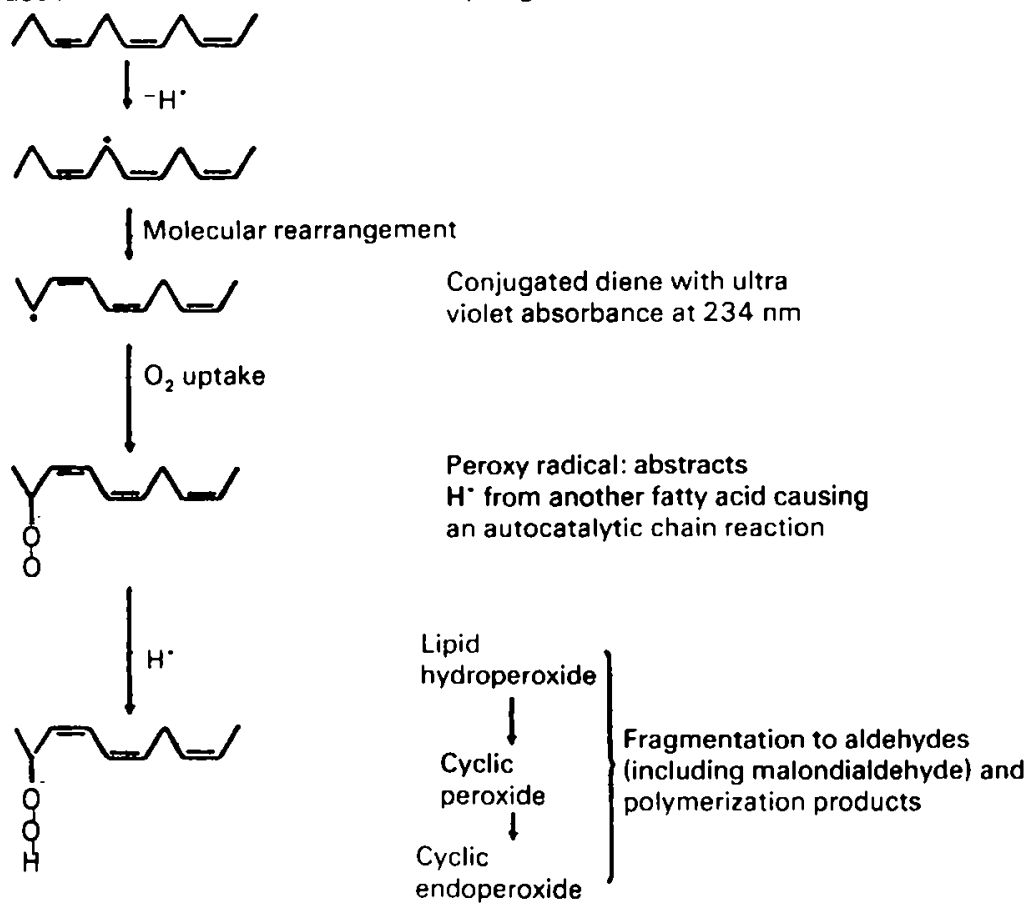

Fig. I. The chain reaction of lipid peroxidation. The structure shows part of a polyunsaturated fatty acid side-chain in a membrane lipid. The hydroxyl radical initiates the process of lipid perodixation by abstracting a hydrogen atom and combining with it to form water. Since a hydrogen atom has only one electron, this leaves behind an unpaired electron on the carbon atom from which it was abstracted (symbolized by '"). This C radical undergoes molecular rearrangement to form a conjugated diene, that then reacts with oxygen to give a peroxy radical. The peroxy radical abstracts a hydrogen atom from an adjacent fatty acid side-chain to continue the process, converting itself into a lipid peroxide. These are stable when pure but in vivo their decomposition is catalysed by copper and iron salts, and their complexes, e.g. haem, methaemoglobin, cytochromes. The decomposition products include radicals that can abstract further hydrogen atoms, as well as hydrocarbon gases and cytotoxic aldehydes. Lipid peroxidation is thus a radical reaction. The antioxidant vitamin $E$ interferes with this chain reaction by donating hydrogen atoms to peroxy radicals, stopping them from initiating.

metal complexes, lipid peroxides decompose to produce many different fragments that include more radicals, hydrocarbon gases and several aldehydes that are highly cytotoxic even in minute amounts. Thus an attack of $\mathrm{OH}^{\circ}$ on a membrane lipid starts off a whole series of radical chain reactions that can severely damage the membrane. The reactions of $\mathrm{OH}^{*}$ with other molecules, such as thymine in DNA, can proceed similarly; there is an initial radical formed, which then reacts with $\mathrm{O}_{2}$ and goes on to bring about further processes.

There is a much-less-reactive oxygen radical, which can be introduced by mentioning the phenomenon of $\mathrm{O}_{2}$ toxicity. $\mathrm{O}_{2}$ is essential for aerobic life, but physiologists have known for years that exposure of aerobic organisms to $\mathrm{O}_{2}$ 
concentrations above those seen normally $\left(2 \mathrm{r} \% \mathrm{O}_{2}\right)$ produces toxic effects. The effects seen depend on the species, age and diet. For example, adult rats die after a few days' exposure to $90-95 \% \mathrm{O}_{2}$. As an illustration of the effect of age, newborn rats are much more resistant to $\mathrm{O}_{2}$. Perhaps the most medically relevant example of $\mathrm{O}_{2}$ toxicity is the retinal damage that can be done to premature babies by exposure to $\mathrm{O}_{2}$ concentrations above normal in incubators. In fact, the $\mathrm{O}_{2}$ concentration in incubators for premature babies is very carefully controlled so that they are given only enough $\mathrm{O}_{2}$ to maintain an acceptable blood oxygen tension and not more, hence minimizing the risk of their developing this retinal degeneration ('retrolental fibroplasia').

The most popular current theory to explain $\mathrm{O}_{2}$ toxicity is the so-called 'superoxide theory of $\mathrm{O}_{2}$ toxicity'. Although not fully proven, there is much evidence consistent with the superoxide theory. It essentially states that the damaging effects of elevated $\mathrm{O}_{2}$ are due to an increase in the formation of the superoxide radical $\left(\mathrm{O}_{2}^{*-}\right)$ within cells, $\mathrm{O}_{2}^{--}$being the one-electron reduction product of $\mathrm{O}_{2}$. The superoxide theory of $\mathrm{O}_{2}$ toxicity was first proposed about 1970 , and supporting evidence came from three lines of work. Firstly, it was shown that the $\mathrm{O}_{2}^{--}$radical could be generated by various systems present in living organisms. For example, some of the electrons passing down the mitochondrial electron transport chain, instead of reaching cytochrome $c$ oxidase ( $E C$ 1.9.3.1), leak directly onto $\mathrm{O}_{2}$ and produce the $\mathrm{O}_{2}^{--}$radical. So the idea that the electron transport chain is a completely efficient transfer of electrons from one component to the next is not quite correct. There are various enzymes present in living systems that produce $\mathrm{O}_{2}^{*-}$ and it has been shown that activated phagocytic cells also produce $\mathrm{O}_{2}^{--}$. In general, the rate of $\mathrm{O}_{2}^{--}$production increases with $\mathrm{O}_{2}$ concentration. For example, if the $\mathrm{O}_{2}$ concentration in mitochondria is increased, there is more leakage of electrons from the electron transport chain. The superoxide-producing enzymes usually have Michaelis-Menten constants $\left(K_{m}\right)$ for $\mathrm{O}_{2}$ that are approximately physiological $\mathrm{O}_{2}$ concentrations, so an increase in $\mathrm{O}_{2}$ concentration gives more $\mathrm{O}_{2}^{\circ-}$ production.

Secondly, the superoxide theory of $\mathrm{O}_{2}$ toxicity is supported by a number of studies which demonstrate that $\mathrm{O}_{2}^{--}$-generating systems can do a great deal of biological damage. To take some examples, exposure of DNA or hyaluronic acid to a $\mathrm{O}_{2}^{--}$-generating system produces degradation; some bacterial strains, and animal cells in culture, are damaged or killed by $\mathrm{O}_{2}^{--}$-generating systems; perfusion of $\mathrm{O}_{2}^{--}$-generating systems into vascular beds produces marked endothelial cell damage; instilling them into the lung of an animal produces oedema, surfactant degradation and cell death. Hence there is a mass of evidence indicating, at least in the test tube, that $\mathrm{O}_{2}^{\circ-}$-generating systems are extremely unpleasant.

The third line of evidence supporting the superoxide theory was the discovery of the enzyme superoxide dismutase ( $E C$ I.I5.I.I) which catalyses the following reaction:

$$
\mathrm{O}_{2}^{--}+\mathrm{O}_{2}^{--}+2 \mathrm{H}^{+} \longrightarrow \mathrm{H}_{2} \mathrm{O}_{2}+\mathrm{O}_{2}
$$


This enzyme is found in almost all aerobic cells. The only known substrate of superoxide dismutase is $\mathrm{O}_{2}^{--}$, it acts catalytically on no other molecule so far tested and studies of the enzyme chemistry show it to be very unlikely that it would act on anything else. So superoxide dismutase is a specific catalyst that evolved to remove $\mathrm{O}_{2}^{--}$by converting it into $\mathrm{H}_{2} \mathrm{O}_{2}$. Superoxide dismutase enzymes have been purified and described in detail from many aerobic cells and much evidence indicates that they function as important biological antioxidants. Interestingly enough, in mammalian (including human) tissues, superoxide dismutase is mainly an intracellular enzyme. Only small amounts are present in extracellular fluids such as plasma, synovial fluid or cerebrospinal fluid.

The action of superoxide dismutase produces $\mathrm{H}_{2} \mathrm{O}_{2}$ which is removed by other enzymes, of which there are two in mammalian cells. These are catalase ( $E C$ I.I I.I.6) which brings about the reaction

$$
2 \mathrm{H}_{2} \mathrm{O}_{2} \longrightarrow 2 \mathrm{H}_{2} \mathrm{O}+\mathrm{O}_{2}
$$

and glutathione peroxidase ( $E C$ I.I I.I.9), which removes $\mathrm{H}_{2} \mathrm{O}_{2}$ by using it to oxidize reduced glutathione (GSH) to oxidized glutathione (GSSG):

$$
2 \mathrm{GSH}+\mathrm{H}_{2} \mathrm{O}_{2} \longrightarrow \mathrm{GSSG}+\mathrm{H}_{2} \mathrm{O}
$$

By far the more important of these two enzymes under normal conditions is glutathione peroxidase. This is probably largely because of the different cellular location of the two enzymes; catalase is located in peroxisomes, whereas glutathione peroxidase is in mitochondria and cytosol, a similar distribution to that of superoxide dismutase.

Glutathione peroxidase is the only known animal enzyme that contains selenium at its active site. Se deficiency in advanced countries is extremely rare, so there is never any need to take extra Se. It has, however, been described in regions of China, where it has been established that a disorder known as Keshan disease, marked by an often fatal cardiomyopathy, is a human Se deficiency. These rural areas of China have very little Se in the soil. The population grows its own food on these soils and does not eat food from other regions. Keshan disease illustrates the importance of glutathione peroxidase as a Se enzyme.

\section{Phagocyte , adical production}

A phagocytic cell such as the neutrophil (the major type of circulating leucocyte in humans) has the function of recognizing a foreign particle such as a bacterium, either because the particle has an unusual surface or, more often, because it has been opsonized in some way. The foreign particle is then engulfed and destroyed. In the plasma membrane of the neutrophil exists an enzyme that seems to have evolved specifically to make the $\mathrm{O}_{2}^{--}$radical, but this enzyme is normally inactive. However, once activated, it takes NADPH from the neutrophil cytosol, oxidizes it to $\mathrm{NADP}^{+}$and passes the electrons onto $\mathrm{O}_{2}$, reducing $\mathrm{O}_{2}$ to $\mathrm{O}_{2}^{--}$outside the cell 


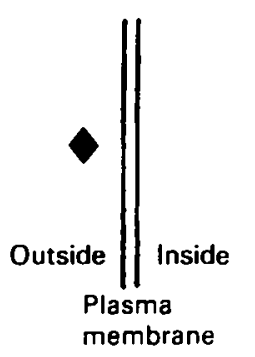

A foreign particle touches the membrane

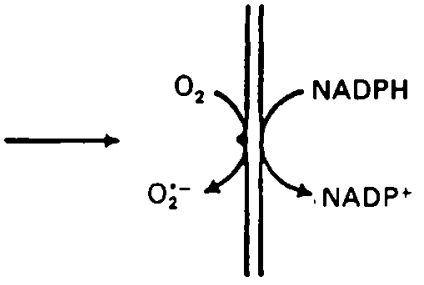

The oxidase complex is switched on and produces extracellular $\mathrm{O}_{2}^{--}$

$$
1
$$

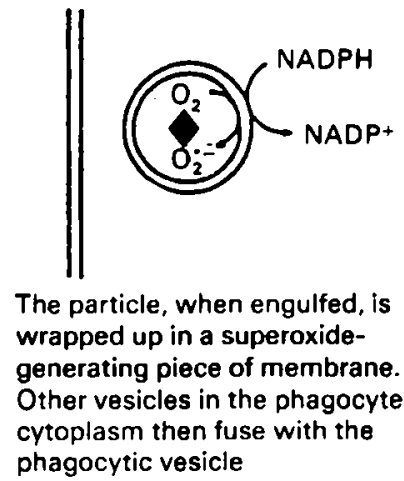

Fig. 2. A schematic representation of the respiratory burst. The engulfed particles are exposed to a flux of superoxide radical $\left(\mathrm{O}_{2}^{-}\right)$inside the phagocytic vacuole.

(Fig. 2). The enzyme is activated whenever a particle that is recognized as foreign, such as an antibody-coated bacterium, touches the surface of the neutrophil. Activation occurs at the point of contact. The piece of plasma membrane in contact is then used to engulf the particle (Fig. 2).

When the particle, enclosed in a phagocytic vacuole formed from $\mathrm{O}_{2}^{0^{-}}$-generating plasma membrane, has entered the cytoplasm of the neutrophil, other things happen. Vesicles fuse with the phagocytic vacuole and empty into it antibacterial proteins, lysosomal proteases and the enzyme myeloperoxidase. Hence there are several potential killing mechanisms in the neutrophil. Which of these mechanisms is important in the killing of a particular strain of bacteria? Perhaps the best way of finding out the importance of something is to stop doing it and see what happens. Exactly this occurs in the inborn error of metabolism known as chronic granulomatous disease. This is an inborn defect in the NADPH oxidase enzyme. There are probably several versions of the disease because the NADPH oxidase is a complicated enzyme with several components. However, they all produce the same effect, the $\mathrm{O}_{2}^{--}$production on membrane contact either does not happen or happens only at a very slow rate. Other aspects of phagocytosis are normal, i.e. the 
foreign particle is still taken into the neutrophil and it still has lysosomal enzymes, myeloperoxidase and antibacterial proteins emptied over it. If neutrophils from patients with this disease are tested for their effectiveness at killing different strains of bacteria, the results tend to fall into two groups. The CGD neutrophils kill some bacterial strains as well as do ordinary neutrophils, so for these strains killing mechanisms other than $\mathrm{O}_{2}^{--}$generation are important. For some other strains, the neutrophils engulf the bacteria but do not kill them. Indeed, the syndrome of chronic granulomatous disease is described as one of persistent and multiple infections with those bacterial strains which seem to require $\mathrm{O}_{2}^{:-}$ production for killing. So $\mathrm{O}_{2}^{*-}$ plays an important role in the neutrophil-mediated killing of several bacterial strains.

One point about the way this 'burst' of $\mathrm{O}_{2}^{--}$production is activated is perhaps worth comment. When the 'foreign particle' touches the neutrophil surface, some of the $\mathrm{O}_{2}^{--}$escapes into the extracellular fluid (Fig. 2), yet extracellular fluids have little superoxide dismutase activity (see p. 22). If $\mathrm{O}_{2}^{--}$is a dangerous and obnoxious species, it would seem more logical to delay the $\mathrm{O}_{2}^{--}$production until the particle is safely inside the cell (see p. 22).

\section{Metals and free-radical reactions}

Up until about 1980 the superoxide theory of $\mathrm{O}_{2}$ toxicity made a lot of sense. It explained the presence of superoxide dismutase. $\mathrm{O}_{2}^{--}$can be produced in vivo and, if the amount of $\mathrm{O}_{2}^{--}$production rises beyond the protective capacity of the enzyme (e.g. at high $\mathrm{O}_{2}$ concentration), damage is produced, especially as many experiments showed that $\mathrm{O}_{2}^{--}$-generating systems were damaging to biomolecules.

Radiation chemists have studied $\mathrm{O}_{2}$ radicals, in particular $\mathrm{OH}^{\prime}$, for many years. They had also studied $\mathrm{O}_{2}^{--}$radical and pointed out that it is the least reactive of any of the $\mathrm{O}_{2}$ radicals. For example, if pure DNA is exposed to pure $\mathrm{O}_{2}^{--}$radical, generated by pulse radiolysis, no reaction is seen. The same is true for hyaluronic acid or membrane lipids. But the 'cruder' experiments mentioned previously showed damage to these molecules by $\mathrm{O}_{2}^{\circ-}$-generation, preventable by superoxide dismutase, although pure $\mathrm{O}_{2}^{--}$is chemically poorly reactive in aqueous solution. The same is true of $\mathrm{H}_{2} \mathrm{O}_{2}$ at the sort of concentrations likely to be present in living organisms.

The idea therefore grew that the biological damage done by $\mathrm{O}_{2}^{-}$-generating systems, such as xanthine oxidase (EC I.I.3.22) plus hypoxanthine or activated phagocytes, is not done directly by $\mathrm{O}_{2}^{*-}$ but occurs because the $\mathrm{O}_{2}^{*-}$ somehow participates in formation of much more reactive species. Three species have been suggested to mediate the biological damage done by $\mathrm{O}_{2}^{--}$-generating systems. The first is singlet oxygen, but this will not be discussed here because there is little evidence that $\mathrm{O}_{2}^{--}$-generating systems produce singlet oxygen under physiological conditions. The second species proposed is the protonated form of $\mathrm{O}_{2}^{--}, \mathrm{HO}_{2}^{\circ}$.

$$
\mathrm{HO}_{2}^{\circ} \mathrm{H}^{+}+\mathrm{O}_{2}^{--}
$$


$\mathrm{HO}_{2}^{\circ}$ is rather more reactive than $\mathrm{O}_{2}^{--}$, but little is present at physiological $\mathrm{pH}\left(\mathrm{p} K_{\mathrm{a}}\right.$ of $\mathrm{HO}_{2}^{-}$is about 4.8 ) and it has yet to be convincingly shown to mediate damage to DNA, proteins or membranes.

Perhaps the most promising proposal is that the reactive species produced in $\mathrm{O}_{2}^{--}$-generating systems is $\mathrm{OH}^{*}$. My group and others were able to show that the $\mathrm{O}_{2}^{--}$-generating systems that had been used in biological experiments were indeed producing this radical. Whatever the system studied, from activated phagocytes to xanthine oxidase, the $\mathrm{OH}^{*}$ production required three things. Firstly, it required $\mathrm{O}_{2}^{*-}$ and so the $\mathrm{OH}^{*}$ production could be suppressed by superoxide dismutase, which explains why superoxide dismutase was producing protective effects. Secondly, it required $\mathrm{H}_{2} \mathrm{O}_{2}$. Thirdly, the $\mathrm{OH}^{*}$ radical was only produced if there was some form of metal-ion catalyst in the reaction mixture. So when all reagents were carefully purified to remove metal-ion contamination, the $\mathrm{OH}^{*}$ radical was no longer formed and the biological damage usually disappeared.

In test-tube experiments, simple salts of titanium, cobalt, iron or copper will promote $\mathrm{OH}^{*}$ formation

$$
\mathrm{O}_{2}^{--}+\mathrm{H}_{2} \mathrm{O}_{2} \underset{\text { catalyst }}{\text { Metal }} \mathrm{OH}^{\bullet}+\mathrm{OH}^{-}+\mathrm{H}_{2} \mathrm{O}
$$

The metal my group has been particularly interested in studying as a promoter of $\mathrm{OH}^{\cdot}$ radical formation in vivo is $\mathrm{Fe}$.

$\mathrm{OH}^{*}$ can be measured in all kinds of ways. One of the commonest is electron-spin resonance (ESR) spin trapping, in which the $\mathrm{OH}^{\circ}$ reacts with a spin trap to produce a stable radical with a well-defined ESR signal. The method I prefer is to allow the $\mathrm{OH}^{*}$ to react with an aromatic ring structure such as salicylate, phenylalanine, benzoic acid or phenol. A set of hydroxylated products is obtained; these can be separated by high-performance liquid chromatography and quantified, usually by electrochemical detection. My group is currently attempting to apply aromatic hydroxylation as a method for measuring $\mathrm{OH}^{\circ}$ formation in vivo. One of the problems in proposing a role for highly reactive species such as $\mathrm{OH}^{*}$ in biological systems is actually proving that they are ever formed in whole organisms. The principle behind our approach is simple. When $\mathrm{OH}^{*}$ attacks aromatic compounds, it produces specific hydroxylated products. If one can find an aromatic compound which is non-toxic, reacts very quickly with $\mathrm{OH}^{*}$ and produces products which are stable and are not identical with those formed by normal metabolic pathways, then one ought to be able, if $\mathrm{OH}^{*}$ is really being formed, to demonstrate the presence of those products in vivo. What aromatic molecules can safely be given to humans in large doses? Many of the non-steroidal anti-inflammatory drugs are aromatic molecules and are currently being studied as 'marker probes' for $\mathrm{OH}^{-}$production, especially as there are many rheumatoid patients being given these drugs.

Fig. 3 is almost a summary of everything described so far. Oxidant stress increases $\mathrm{O}_{2}^{--}$and $\mathrm{H}_{2} \mathrm{O}_{2}$ production. In the presence of metals these are converted into $\mathrm{OH}^{\cdot}$ that do direct damage, which results in other (e.g. peroxy) radical 


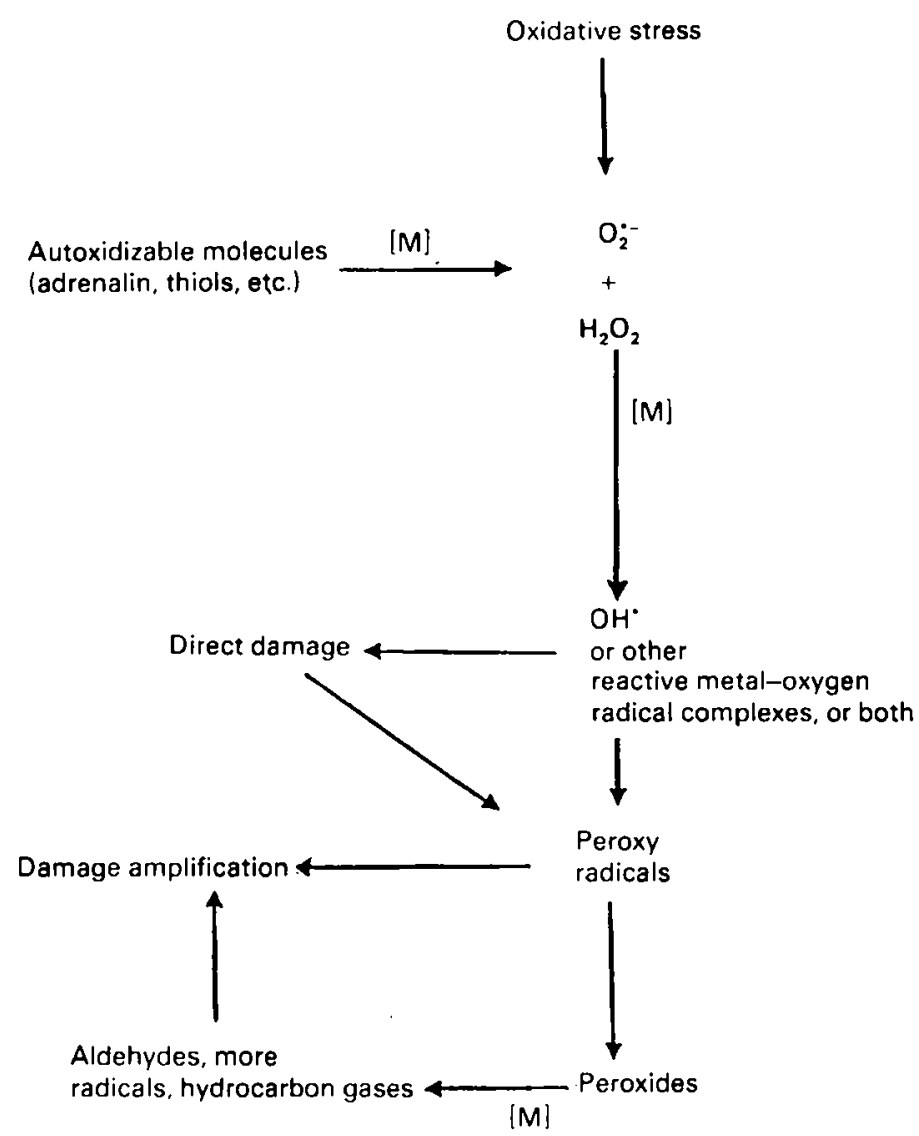

Fig. 3. Involvement of metal ions $[M]$ in free-radical reactions.

formation that makes the damage worse. Metals are involved in lipid peroxide decomposition. Some of the autoxidation reactions that produce $\mathrm{O}_{2}^{:-}$and $\mathrm{H}_{2} \mathrm{O}_{2}$ in vivo are accelerated by metal ions. Hence, as shown in Fig. 3, metal ions are intimately involved in free-radical reactions, particularly $\mathrm{Fe}$.

Suppose that we are right in proposing that the damage done by $\mathrm{O}_{2}^{--}$and $\mathrm{H}_{2} \mathrm{O}_{2}$ is not direct damage but occurs because of $\mathrm{OH}^{*}$ production. That leads to another conclusion. Because of its high reactivity, $\mathrm{OH}^{*}$ will not get very far from its site of formation. Hence what really determines the nature of the damage done by $\mathrm{O}_{2}^{*-}$ and $\mathrm{H}_{2} \mathrm{O}_{2}$ is the location within the organism of metal ion complexes that will promote $\mathrm{OH}^{*}$ formation. In other words, it is not just how much $\mathrm{O}_{2}^{*-}$ or $\mathrm{H}_{2} \mathrm{O}_{2}$ that is generated, it is whether it occurs in regions of the cell that contain metal-ion promoters of $\mathrm{OH}^{\circ}$ formation. For example, if there are metals bound to DNA then DNA fragmentation will result, but if the metals are stuck to membrane lipids there will be lipid peroxidation. Hence the nature of biological damage done by $\mathrm{O}_{2}^{*-}$ and $\mathrm{H}_{2} \mathrm{O}_{2}$ is not necessarily predictable from the chemistry of $\mathrm{OH}^{\circ}$. The damage 
depends on where $\mathrm{OH}^{*}$ is formed, which depends on where the metal-ion promoters are located.

The previously-described concept led us into two lines of research. The first and obvious one: what are the physiological metal promoters of $\mathrm{OH}^{\circ}$ formation? We have largely concentrated on $\mathrm{Fe}$. $\mathrm{Fe}$ is transported around the body attached to the protein transferrin. It is stored in the protein ferritin and it seems to be accepted that there is a small intracellular low-molecular-weight $\mathrm{Fe}$ pool that donates $\mathrm{Fe}$ to Fe-proteins. Fe is unloaded from transferrin within the cell, the excess goes into ferritin and in between there is this small Fe pool. Its chemical nature is unclear, but experts in the $\mathrm{Fe}$ field think that it probably consists of low-molecular-weight Fe chelates, Fe being attached to ligands such as ATP, ADP or citrate and possibly attached loosely to various proteins and to cell membranes. All these forms of $\mathrm{Fe}$ can be shown to promote $\mathrm{OH}^{*}$ formation and lipid peroxide decomposition. Hence the internal cellular $\mathrm{Fe}$ pool is a candidate for allowing damaging radical formation to occur (Fig. 3).

A second possibility is the protein ferritin. My group and others have shown that if ferritin is added to radical-generating systems, it promotes $\mathrm{OH}^{*}$ formation and lipid peroxidation, although not as effectively as the equivalent amount of 'free' Fe salt. Hence having Fe locked up in ferritin is safer than having it floating around as low-molecular-mass $\mathrm{Fe}$ complexes. What seems to happen is that $\mathrm{O}_{2}^{\circ-}$ can cause release of $\mathrm{Fe}$ from ferritin, and then use that $\mathrm{Fe}$ to promote $\mathrm{OH}^{*}$ production. Similarly, lipid peroxides damage the ferritin protein and cause a release of Fe. Ferritin-accelerated radical reactions are inhibitable by the chelator desferrioxamine, which binds the Fe released from the ferritin molecules. Hence ferritin is not always a 'safe' form of $\mathrm{Fe}$ when radicals are being generated. We have recently shown that the protein haemosiderin is much less active in releasing $\mathrm{Fe}$ and promoting radical reactions than is ferritin.

Finally, one must consider the $\mathrm{Fe}$ transport protein transferrin, and a similar protein (lactoferrin) secreted by neutrophils. There is much debate in the literature about whether these two proteins are physiologically important promoters of $\mathrm{OH}^{*}$ formation. In our hands they are not; in fact they will usually inhibit $\mathrm{OH}^{\circ}$ formation and lipid peroxidation. The only groups who have reported them as active in promoting radical reactions have used fully Fe-loaded proteins, with 2 mol Fe ${ }^{3+} /$ mol protein. I think they have observed an artefact, but certainly in our hands we never find that either transferrin or lactoferrin are promoters of $\mathrm{O}_{2}$ radical reactions at physiological $\mathrm{pH}$. In fact, we proposed some time ago that one of the reasons why neutrophils release lactoferrin is to help protect themselves or the surrounding tissue from any extraneous $\mathrm{Fe}$ that may be available. Binding that $\mathrm{Fe}$ may diminish damage by slowing down the rate at which any $\mathrm{O}_{2}^{--}$generated is converted into $\mathrm{OH}^{\circ}$. However, at acidic $\mathrm{pH}$ values transferrin does release its $\mathrm{Fe}$ (as it has evolved to do within the cell). The value usually quoted for the $\mathrm{pH}$ at which transferrin releases $\mathrm{Fe}$ is around 5.5 . However, in the microenvironment of activated phagocytic cells the $\mathrm{pH}$ may drop to a similar value. Hence it is possible that transferrin may be a source of $\mathrm{Fe}$ to activated phagocytic cells and promote 
$\mathrm{OH}^{*}$ formation, but at normal physiological $\mathrm{pH}$ we never find that transferrin or lactoferrin will do anything except protect (by binding 'free $\mathrm{Fe}$ ') in our systems. Also, lactoferrin does not release its $\mathrm{Fe}$ at $\mathrm{pH}$ 5.5; much lower $\mathrm{pH}$ values are required.

\section{Extracellular antioxidant protection}

In view of the previously-described information, we have begun to think again about the nature of antioxidant protection. Within cells, it is agreed that there is some form of low-molecular-mass transit pool of Fe. Hence Fe promoters of $\mathrm{OH}^{\circ}$ formation and lipid peroxidation exist, but there are superoxide dismutase, catalase and glutathione peroxidase. It could be argued that these enzymes provide the major intracellular antioxidant protection by removing $\mathrm{O}_{2}^{--}$and $\mathrm{H}_{2} \mathrm{O}_{2}$, hopefully before they ever get anywhere near the available $\mathrm{Fe}$ promoters. However, in extracellular fluids there is very little superoxide dismutase or Se glutathione peroxidase and no catalase. The major antioxidant protection of extracellular fluids, we argue, is something very different. It is simply that, under normal conditions, there are no $\mathrm{Fe}$ catalysts of radical reactions available. Hence $\mathrm{O}_{2}^{;-}$and $\mathrm{H}_{2} \mathrm{O}_{2}$ can be generated in reasonable quantities and they will not do a great deal of damage. So, in extracellular fluids, there is an excess of transferrin; much more than is necessary to carry the amount of Fe that is normally carried. There is the protein caeruloplasmin, one of whose enzymic activities is its ability to oxidize $\mathrm{Fe}^{2+}$ to $\mathrm{Fe}^{3+}$. Uric acid has been proposed as an antioxidant recently. In many of the experiments demonstrating the antioxidant action of uric acid it is probably acting by binding metals. The large amounts of plasma albumin, with its high-affinity binding site for $\mathrm{Cu}$, will quickly bind any $\mathrm{Cu}$ released into plasma. Hence we argue that extracellular antioxidant protection is not directed towards removing $\mathrm{O}_{2}^{--}$and $\mathrm{H}_{2} \mathrm{O}_{2}$, but is directed to stopping them reacting together and making the real damaging species $\mathrm{OH}^{*}$.

One could then ask 'why should organisms have evolved to do that, why not just have superoxide dismutase, catalase and glutathione peroxidase in extracellular fluids?'. A possible answer is that the extracellular radical production by activated phagocytic cells discussed previously is useful in some way. Evidence suggests that $\mathrm{O}_{2}^{--}$and $\mathrm{H}_{2} \mathrm{O}_{2}$ are involved in chemotactic signalling between cells by some mechanism, and that they interact with the products of arachidonic acid metabolism. To do this, one must stop or slow the rate at which the $\mathrm{O}_{2}^{\circ-}$ and $\mathrm{H}_{2} \mathrm{O}_{2}$ form $\mathrm{OH}^{\circ}$, that would do considerable damage.

\section{Free radicals and human disease}

I mentioned in the introduction that radicals are involved in many diseases. I can go further and say that one can demonstrate increased radical reactions in almost any disease. That is not the same as saying that the increased radical reactions are important or have anything to do with the origin of the disease. We have seen that metal ions such as $\mathrm{Fe}$ are important in radical reactions, and that organisms are very careful in how they handle metal ions. As soon as a tissue is 
injured by infection, trauma, or by the action of some toxin, cells are damaged and may release mobile cellular Fe pools. Lysosomal enzymes can be released, hydrolyse metallo-enzymes and provide more metals. Hence the 'decompartmentalization' of metal ions in damaged tissue will itself give more radical reactions. For example, analysis of muscle tissue from patients with muscular dystrophy for end-products of free-radical reactions shows them to be present, but no one seriously suggests that muscular dystrophy is caused by increased free-radical reactions. There is tissue damage by an unknown cause and more radical reactions, consequent on the damage. Hence one must be very careful in reading the literature about 'free radical activity in disease'. The mere fact that radical reactions can be demonstrated does not mean that radical reactions are important or causative in the particular disease under study. This is quite a simple point but often missed.

One tissue that is very prone to increased free-radical reactions on damage is brain. Unlike plasma and normal synovial fluid, cerebrospinal fluid has very little in the way of metal-binding capacity, so that $\mathrm{Fe}$ complexes released into cerebrospinal fluid from damaged brain tend to stay there and are available to promote radical reactions. Damaged brain undergoes lipid peroxidation at a fast rate.

Our second line of work is that, if what we are saying is true, can we protect against oxidative damage by using chelating agents, reagents that bind metals and stop them participating in free-radical reactions? In the late 1970 sy group screened a large number of Fe-chelating agents to see how they affected Fe-stimulated $\mathrm{OH}^{\circ}$ production and lipid peroxidation. Several inhibitory chelators were discovered, the best one at the time being the compound desferrioxamine. Desferrioxamine was of interest because it is approved for clinical use in $\mathrm{Fe}$ overload, seemed remarkably safe in the treatment of $\mathrm{Fe}$ overload and is much more specific for $\mathrm{Fe}$ (although not absolutely specific) than any of the other chelators found to be protective. Hence desferrioxamine was studied in detail. We found that it was not only a powerful chelator of $\mathrm{Fe}^{3+}$, but also a direct scavenger of $\mathrm{OH}^{*}$ with a remarkably high rate constant, and a powerful inhibitor of Fe-dependent lipid peroxidation and $\mathrm{OH}^{\circ}$ production. It even reacts with $\mathrm{O}_{2}^{;-}$, but with a fairly low rate constant, so its inhibition of Fe-dependent processes and its direct scavenging of $\mathrm{OH}^{*}$ are the major components of its antioxidant role. One action of desferrioxamine that might not be so good is its ability to accelerate mobilization of $\mathrm{Fe}$ from ferritin by reducing agents. Although ferritin-Fe is not harmless, it is much safer than low-molecular-mass Fe (see p. 21). In collaboration with Dr David Blake in Birmingham we studied the action of desferrioxamine on various animal models of inflammation, and several other groups started using desferrioxamine to see what it would do in other systems in which oxidative damage is important. Table $I$ is a summary of the results that have been reported in the literature to date. Of especial note is the ability of desferrioxamine to diminish neutrophil-mediated acute lung injury in rats after complement activation (an alleged model for the adult respiratory distress 


\section{Table 1. Demonstrated effects of desferrioxamine on biological systems}

I. Decreases ethanol clearance in rats.

2. Decreases neutrophil-mediated acute lung injury in rats after complement activation.

3. At high doses is anti-inflammatory in acute and acute-to-chronic animal models of inflammation.

4. Blocks the haemolytic action of several radical-generating drugs in mice.

5. Decreases carbon tetrachloride-induced hepatotoxicity in animals.

6. Inhibits the progress of an autoimmune disease model in rats.

7. Decreases killing of hepatocytes by hydrogen peroxide.

8. Decreases paraquat and alloxan toxicity in animals (in some experiments only).

9. Protective against reperfusion damage after ischaemia in heart and kidney.

10. Enhances the survival of activated human neutrophils.

11. Increases the survival time and decreases the side-effects seen in Fe-overloaded human patients.

syndrome). It is anti-inflammatory at high doses in a number of animal model systems but, interestingly, at low doses it is sometimes pro-inflammatory. It diminishes reperfusion injury after ischaemia, blocks the haemolytic action of several radical-generating drugs in mice, has been shown in some experiments to decrease paraquat toxicity in animals and has been reported as helpful in a few uncontrolled trials of degenerative disorders.

The results in Table I appear to support our theories; by putting in a chelating agent that would bind $\mathrm{Fe}$ and stop it participating in radical reactions, oxidative damage in these various animal models was often diminished. This, of course, does not mean that desferrioxamine is therapeutically useful for humans (it may be too powerful an Fe-chelating agent). What might be needed for prevention of oxidative damage is a chelating agent that will bind 'free' Fe but not take Fe out of Fe-proteins. Such a chelator might not be ideal for treatment of Fe overload, of course.

Finally, I will move on to one of the diseases we have been especially interested in, rheumatoid arthritis. The inflamed rheumatoid joint swarms with phagocytic cells producing $\mathrm{O}_{2}^{--}$and $\mathrm{H}_{2} \mathrm{O}_{2}$, and analysis of synovial fluid from rheumatoid patients shows that it often contains $\mathrm{Fe}$ in a form that will promote $\mathrm{OH}^{\circ}$ formation. $\mathrm{OH}^{*}$ would be expected to damage membranes, hyaluronic acid, antiproteases etc. So, we aimed to answer two questions. Firstly, is there evidence for increased free-radical generation in human rheumatoid disease? Secondly, and more importantly in clinical terms, is the free-radical generation making a significant contribution to the joint damage?

I mentioned that the synovial fluid of rheumatoid patients often contains $\mathrm{Fe}$ in a form that will promote radical reactions. The amount of this Fe present, as measured by a technique developed by Dr John Gutteridge (the 'bleomycin assay'), is strongly correlated with disease activity, as assessed by physical examination 
(done by clinicians unaware of laboratory results) or laboratory indices (acute phase protein determination, synovial fluid white cell count, erythrocyte sedimentation rate). So the worse the disease is, the more $\mathrm{Fe}$ tends to be present in ths synovial fluid. Analysis for end-products of lipid peroxidation shows the same trend; the worse the disease activity, the more end-products of lipid peroxidation.

What these studies mean is that, as the disease gets worse, there are more radical reactions and there seem to be more metal promoters of radical reactions. In the synovial membrane of the rheumatoid joint increased deposition of Fe-proteins such as ferritin and haemosiderin is seen. These studies do not, of course, prove that the increased radical reactions and the increased $\mathrm{Fe}$ deposition are causing the inflammation to get worse. It might be the other way round; as the inflammation gets worse you get more damage and destruction and more radical reactions. It was an attempt to clarify this issue that prompted us to start the studies, on desferrioxamine as an anti-inflammatory agent in animal models, referred to previously. They did show quite clearly an anti-inflammatory effect of desferrioxamine in acute and acute-to-chronic models of inflammation. Radical-scavenging activity may also be involved in the action of a number of non-steroidal anti-inflammatory drugs. $\mathrm{OH}^{*}$ is so reactive that it combines with almost anything, including most non-steroidal anti-inflammatory drugs. Some of these drugs might also bind $\mathrm{Fe}$ in a way that affects its reactivity in promoting radical reactions. It may be an idea to attempt to build metal-binding capacity into the design of new anti-inflammatory drugs in a way that inhibits radical reactions.

In summary, radical reactions are not of esoteric interest, but occur all the time. They are of minor importance in some diseases and of greater importance in others, such as rheumatoid arthritis. Radical reactions are not always damaging; they are often used for useful processes of which the prime example, as discussed previously, is phagocyte $\mathrm{O}_{2}$-radical production. Other areas in which they are important are the chemistry of cyclooxygenase and lipoxygenase enzymes, cytochrome $\mathrm{P}_{45}$, other hydroxylating enzymes and dioxygenases. Nucleoside diphosphate reductase, important in DNA replication, is an enzyme whose activity depends on a tyrosine radical. Thus there are many examples of free radicals that have been put to a useful purpose in biological systems. The normal free-radical production by activated phagocytic cells is very useful in bacterial killing and perhaps in cellular communication. Only when it becomes abnormally high, e.g. in rheumatoid disease, in the presence of metal promoters that can convert the $\mathrm{O}_{2}^{*-}$ and $\mathrm{H}_{2} \mathrm{O}_{2}$ produced into more reactive species, can a lot of biological damage result.

\section{BIBLIOGRAPHY}

Aruoma, O. I. \& Halliwell, B. (1987). Biochemical fournal 241, 273-278.

Grootveld, M. \& Halliwell, B. (1986). Free Radical Research Communications 1, 243-250.

Halliwell, B. \& Gutteridge, J. M. C. (1985). Free Radicals in Biology and Medicine. Oxford: Clarendon Press.

Halliwell, B. \& Gutteridge, J. M. C. (1985). Molecular Aspects of Medicine 8, 89-193. 
Halliwell, B. \& Gutteridge, J. M. C. (1986). Archives of Biochemistry and Biophysics 246, 50I-514.

Halliwell, B., Gutteridge, J. M. C. \& Blake, D. (1985). Philosophical Transactions of the Royal Society, Series B 31 r, 659-671. 